DOI: 10.20472/IAC.2018.039.023

\author{
ALINA KLEIN \\ University of Dubuque, United States \\ RUDOLF KLEIN \\ University of Dubuque, United States
}

\title{
MEAN REVERSION AND MOMENTUM IN CENTRAL AND EASTERN EUROPEAN COUNTRIES - A CASE STUDY ON POLAND AND ROMANIA
}

\begin{abstract}
:
There is considerable evidence that both mean reversion and momentum exist in stock prices, especially in well developed countries. We analyze these phenomena for two Central and Eastern European countries that experienced very different transitions from centrally-planned to market economies: Poland and Romania. While being considered an emerging market, Poland's stock market capitalization increased from 3 percent of GDP in 1995 to about 30 percent in 2017. Romania's stock market capitalization in the 1990s and early 2000s was less than 6 percent of GDP and only recently increased to about 21 percent. We examine how mean reversion and momentum have affected stock prices in these two very different emerging economies and we find very similar results. For both, the speed at which stocks converge back to their fundamentals (i.e., mean reversion) is much faster than that of the developed markets, with half-lives only slightly greater than 9 months. These results are similar to the ones obtained for the Chinese market (see Wu, 2011), but much shorter than the 3-4 years found for the well-developed economies. We also find that, similarly to the Chinese market, the momentum effect is weak. As a result, in most cases, a strategy combining mean reversion and momentum generates abnormal excess returns only for holding periods of less than 12 months.
\end{abstract}

\section{Keywords:}

Transition Economies, Mean Reversion, Momentum, International Asset Pricing Model, Investment Strategies

JEL Classification: G12, G14, P34 